\title{
ANÁLISE DAS FALHAS NO SERVIÇO DE MANUTENÇÃO DE UMA PETROQUÍMICA POR MEIO DAS FERRAMENTAS DA QUALIDADE
}

\section{FAILURE ANALYSIS IN THE PETROCHEMICAL MAINTENANCE SERVICE THROUGH QUALITY TOOLS}

Recebido em: 12 jul. 2018

Aprovado em: 11 mar. 2020

Versão do autor aceita publicada online: 11 mar. 2020

Publicado online: 12 maio 2021

\section{Como citar esse artigo - American Psychological Association (APA):}

Silva, D. C. S., \& Correia, A. M. M. (2021, out./dez.). Análise das falhas no serviço de manutenção de uma petroquímica por meio das ferramentas da qualidade. Exacta. 19(4), 817-842. https://doi.org/10.5585/exactaep.2021.8894.

Submeta seu artigo para este periódico $\beta$

Dados Crossmark 


\title{
ANÁLISE DAS FALHAS NO SERVIÇO DE MANUTENÇÃO DE UMA PETROQUÍMICA POR MEIO DAS FERRAMENTAS DA QUALIDADE
}

\author{
FAILURE ANALYSIS IN THE PETROCHEMICAL MAINTENANCE SERVICE THROUGH \\ QUALITY TOOLS
}

Dayse Camila Saraiva Silva ${ }^{1}$

Ana Maria Magalhães Correia ${ }^{2}$

\footnotetext{
${ }^{1}$ Especialista em Gestão Estratégica de Serviços Universidade Federal Rural do Semi-Árido - UFERSA. Mossoró, Rio Grande do Norte - Brasil. engdaysesaraiva@gmail.com

2 Doutora em Administração Universidade Federal da Paraíba - UFPB. Mamanguape, Paraíba - Brasil. anamagalhaes@ccae.ufpb.br
}

Recebido em: 12 jul. 2018

Aprovado em: 11 mar. 2020
Resumo: O objetivo desse artigo foi analisar as falhas no serviço de manutenção de uma petroquímica por meio das ferramentas da qualidade. Os objetivos específicos foram: (i) mapear o processo do serviço de manutenção, (ii) utilizar ferramentas da qualidade para organizar e tratar os dados referentes às falhas e (iii) propor um plano de ação para eliminação dessas causas. A pesquisa é classificada qualitativa e quantitativa, descritiva e exploratória. Os dados foram coletados através de entrevistas semiestruturadas e análise documental. Os resultados mostram que as falhas A e C são decorrentes de grupos de falhas mecânicas com duração de tempo de 9,75 e 1,33 respectivamente e a falha B com duração de 6,42 é decorrente de grupos de falhas elétricas no setor estudado. Conclui-se que as ferramentas da qualidade auxiliaram no gerenciamento das falhas, possibilitando organização dos dados, isolamento das falhas, exploração e identificação das causas e elaboração de planos direcionando a resolução das mesmas.

Palavras-chave: Manutenção. Análise das falhas. Petroquímica. Ferramentas da Qualidade.

Abstract: The objective of this article was to analyze the failures in the service of maintenance of a petrochemical through the tools of quality. The specific objectives were: (i) to map the maintenance service process, (ii) to use quality tools to organize and handle data concerning failures and (iii) propose a plan of action to eliminate these causes. The research is classified qualitative-quantitative, descriptive and exploratory. Data were collected through semi-structured interviews and documentary analysis. The results show that failures $A$ and $C$ resulting to mechanical failures with time duration of 9.75 and 1.33 respectively and fault $B$ with duration of 6.42 is resulting to electrical failure in the studied sector. It was concluded that the quality tools aided in the management of failures, allowing data organization, fault isolation, exploration and identification of causes and elaboration of plans directing their resolution.

Keywords: Maintenance. Failure analysis. Petrochemical. Quality tools. 


\section{Introdução}

Em todas as organizações, dos mais variados segmentos, é possível perceber a importância da qualidade e a necessidade de políticas para assegurar seu contínuo controle.

Carpinetti (2012) explica que, a partir da década de 50, a qualidade, que até então era relacionada apenas à percepção técnica do produto, evoluiu para a adequação ao uso, sendo assim desdobrada em várias características ou atributos. Desta forma, a análise das falhas representou, em muitos casos, a garantia de sobrevivência das empresas, tamanha é a vigilância e a cobrança da sociedade (Almeida, Leal, Pinho \& Fagundes, 2006). Rausand e Oien (1996) definem falha como sendo o fim da habilidade de um item executar uma função exigida. Nesse sentido, o intuito é garantir a conformidade de produtos e/ou serviços com suas especificações ou seu projeto e, consequentemente, a satisfação dos clientes, sejam eles internos, intermediários ou finais. Desse modo, a qualidade pode ser definida como todas as propriedades ou características de um produto ou serviço relacionadas à sua capacidade de satisfazer as necessidades explícitas ou implícitas dos que o utilizam (Lacombe \& Heilborn, 2006).

Mello (2011) afirma que a qualidade é uma questão que precisa ser adequadamente gerida no contexto de uma organização e, por essa razão, empreendedores e administradores de todos os níveis precisam conhecer a chamada gestão da qualidade. Para Crosby (1999), a gestão da qualidade é um meio sistemático de garantir que as atividades organizadas aconteçam segundo o planejado, ou seja, diz respeito à criação de atitudes e controles que possibilitam a prevenção de problemas. Para Almeida et al., (2006) é necessário primeiramente identificar e analisar os problemas, ou seja, as falhas que existem em determinado bem ou serviço. Mais especificamente, para buscar a solução da consequência indesejada é necessário atuar a partir de seus fatores causadores.

Segundo Ganim (2003), a gestão de falhas de uma empresa está diretamente ligada ao incremento da produtividade, permitindo a adequada alocação dos recursos em busca de maior qualidade. Mello (2011) acrescenta que gerir a qualidade significa disseminá-la nas organizações, de modo que ela passe a fazer parte do modo de pensar de todos e não apenas do modo de fazer. E, para que isso aconteça, os profissionais da qualidade têm, à sua disposição, inúmeras ferramentas e programas. Neste contexto, surge a importância das ferramentas da qualidade, que, segundo Vieira (2012), são um conjunto de técnicas gráficas que permitem resolver boa parte dos problemas estatísticos que surgem no decorrer da análise de dados quando a intenção é manter a qualidade.

As ferramentas da qualidade são os elementos que permitem operacionalizar efetivamente os preceitos da gestão da qualidade. Eles são os instrumentos utilizados para o desenvolvimento, medição, análise e melhoria da qualidade nas organizações. Assim, permitem a identificação e solução dos 
principais problemas organizacionais e, por este motivo, são importantes instrumentos de diferenciação organizacional (Bamford \& Greatbanks, 2005; Alsaleh, 2007).

É importante destacar que o uso das ferramentas da qualidade, não se restringe à fabricação de produtos, mas abrange também o setor de serviços. Seleme (2016) afirma que a análise histórica permite-nos deduzir que o setor manterá, com pequenas variações, a mesma proporção diante do PIB, o que se traduz num fator importante para a análise das organizações do desenvolvimento e no fornecimento dos serviços.

Dessa forma, de acordo com o Instituto Brasileiro de Geografia e Estatística - IBGE, o setor de serviços em 2017, apresentou resultado positivo no crescimento do PIB em comparação com 2016 nos setores do comércio (1,9\%), atividades imobiliárias e outros serviços $(0,8 \%)$ e atividade de transporte, armazenagem e correio (0,6\%). É o segmento de maior peso na economia brasileira. Ele responde sozinho por quase $75 \%$ do PIB (Ibge, 2018). A importância dessa atividade na sociedade pode ser demonstrada tanto pela posição que ocupa na economia no tocante à contribuição do PIB e geração de empregos, quanto pela análise das tendências e transformações que a economia mundial está vivenciando (Corrêa \& Gianese, 2012).

O estudo dos serviços, por sua vez, pode ser demasiadamente complexo em virtude da quantidade de variáveis, subjetividade e intangibilidade envolvidas. Porém, tornam-se cada vez mais relevante, já que os serviços estão presentes nas nossas vidas nas mais variadas formas. Lovelock, Wirtz e Hemzo (2011) definem serviços como atividades econômicas, geralmente baseadas no tempo, oferecidas por uma parte a outra, cujo desempenho leva a seus destinatários os resultados desejados. Seleme (2016) acrescenta que os serviços podem ser fornecidos sozinhos ou combinados com bens físicos, em diversas proporções.

Xenos (2014) explica a manutenção como um serviço e afirma que, como em qualquer outro serviço, a qualidade na manutenção é determinada pelo trabalho humano, ou seja, conhecimento e habilidade daqueles que a executam. Como também pela modernização dos equipamentos, a automação dos sistemas e processos, a diversidade e a quantidade de componentes e acessórios utilizados crescentemente nas instalações industriais (Nunes, 2001).

Nunes (2001) complementa que em função disso, a responsabilidade a ser assumida pelas áreas de manutenção tende a ser bem mais abrangente. Assim, a manutenção representa uma das atividades fundamentais no processo produtivo organizacional, ao ser vista como mola propulsora, que pode levar uma empresa a destacar-se, a partir de diferenciais competitivos (Chavez \& Medeiros, 1998).

Diante desse contexto, o estudo proposto foi desenvolvido no âmbito de uma empresa do ramo petroquímico, no setor de manutenção, motivado pela necessidade de otimização do gerenciamento das falhas em equipamentos e possui a seguinte pergunta de pesquisa: Como as ferramentas da 
qualidade podem ser aplicadas no setor de manutenção para auxiliar no gerenciamento e análise das falhas?

A busca sistemática recente pelos estudos acadêmicos nas bases nacionais e internacionais (Web of Science, Scopus, Emerald) dissertações e teses (Bancos de dissertações e teses) sobre análises de falhas demonstra que esses estudos tratam do feito interativo de falhas (Leal, 2008), análise de falhas para o desenvolvimento de produtos (Sakurada, 2001; Laurenti, 2010). A respeito do uso das ferramentas da qualidade, a aplicação das mesmas se dão em empresas de autopeças (Trivellato, 2010), organizações portuguesas (Pacheco, 2012), indústria de ração (Fabris, 2014) e de reciclagem e bebidas (Costa, 2017). Entretanto, nenhum destes trata da análise de falhas por meio das ferramentas da qualidade em uma petroquímica. É precisamente a inexistência ou, pelo menos, a escassez de pesquisas sobre análise de falhas no serviço de manutenção por meio das ferramentas da qualidade em uma petroquímica que se justifica a presente pesquisa.

Na busca pela reposta à pergunta da pesquisa, o objetivo geral desse trabalho é analisar as falhas no serviço de manutenção de uma petroquímica por meio das ferramentas da qualidade. Os objetivos específicos traçados para o alcance do objetivo geral são: (i) mapear o processo do serviço de manutenção, (ii) utilizar as ferramentas da qualidade para organizar e tratar os dados referentes às falhas, identificando as principais causas potenciais e (iii) propor um plano de ação para eliminação dessas causas identificadas.

\section{Referencial teórico}

\subsection{Ferramentas da qualidade}

A gestão da qualidade tem como objetivos a padronização de processos e, por meio de planejamento, controle e aprimoramento, a garantia da qualidade de produtos e serviços. Segundo Srdoc, Sluga e Bratko (2005) e Lagrosen (2007) as empresas necessitam adotar um sistema que priorize a qualidade em suas decisões para que seja possível alcançar e manter a qualidade de seus processos, produtos e serviços. Nesse sentido, o conceito de qualidade é amplo e pode variar dependendo do setor onde está sendo empregado. Dentre tantos autores desta área, pode-se citar Crosby (1999), que define a qualidade, de maneira objetiva, como conformidade às exigências ou o pleno cumprimento dos requisitos. Já Ishikawa (1993), fornece uma visão mais abrangente, destacando, inclusive, o papel social da empresa, no momento que educa e forma seus integrantes, promovendo a qualidade de vida dos seus colaboradores e até da nação.

Para a maioria dos clientes, qualidade relaciona-se às características do produto que atendem suas necessidades. Além disso, qualidade quer dizer ausência de falhas, bem como um bom serviço ao cliente. Uma definição abrangente para isso é “adequação ao uso" (Juran \& Gryna, 1991, p. 43). 
Para Matias (2014) nesse cenário são utilizadas ferramentas da qualidade, aumentando a eficiência no alcance dos objetivos e na utilização de todos os recursos, desde humanos a materiais e financeiros. As metodologias de trabalho que orientam a resolução de problemas de qualidade ao longo de todo processo de transformação, vem sendo amplamente aplicadas, visto que estas ferramentas auxiliam na redução contínua dos gastos, redução de desperdícios e na otimização de custos de produção garantindo a sustentabilidade do negócio num mercado cada vez mais competitivo.

Inúmeros estudos dão conhecimento que com o uso das ferramentas da qualidade foi possível obter sucesso e melhorias de um processo, produto ou serviço como, por exemplo, em empresas de autopeças (Trivellato, 2010), supermercados (Brito, Bezerra \& Oliveira, 2011), de ração (Fabris, 2014), empresas do setor metal mecânico (Mello, Araújo, Cunha \& Silva, 2016), de pintura (Coelho, Silva \& Maniçoba, 2016) e de bebidas (Costa, 2017). Pacheco (2012) também salienta que são vários os estudos (Dias \& Saraiva, 2004, Sergesketter, 2004, Courtney, 2005, Sousa, Aspinwall, Sampaio \& Rodrigues, 2005, Thiravian, 2006, Jacobsen, 2009 e Schaar, 2010) que mencionam que através da utilização de ferramentas da qualidade é possível encontrar soluções e delinear estratégias para a resolução de problemas.

Segundo Hlioui, Gharbia e Hajjib (2015), toda a empresa deve estar voltada para a tarefa de dar qualidade e padronização aos produtos, bem como fazer inspeções constantes, sendo este item crucial para manter a padronização e qualidade dos produtos. Conforme explica Mello (2011), as ferramentas da qualidade não foram criadas para uso isolado, mas para que, juntas, possam ajudar a mapear os defeitos de produtos e serviços, encontrar suas causas e corrigi-las dentro do processo. Segundo o autor, não existem fórmulas de combinação dessas ferramentas, mas cada uma tem especificidades que estão devidamente esclarecidas para que sejam reconhecidas e usadas adequadamente de acordo com a necessidade.

Nesse sentido, utilizadas para desenvolver, implementar, monitorar e melhorar os preceitos da qualidade nas organizações, as ferramentas da qualidade representam importantes e necessários instrumentos para que a gestão da qualidade obtenha máxima eficiência e eficácia (Bamford \& Greatbanks, 2005; Alsaleh, 2007). Avaliar a satisfação do cliente, visando à melhoria da qualidade nos produtos e serviços, é uma das importantes funções competitivas das ferramentas da qualidade. Essa prática promove a confiabilidade e produz consideráveis vantagens à empresa em relação aos seus concorrentes (Carnevalli, Miguel \& Calarge, 2008).

Vieira (2012) explica que a denominação ferramentas estatísticas de qualidade surgiu no Japão, logo após o final da Segunda Guerra Mundial. As empresas precisavam capacitar mão de obra para o controle da qualidade, mas não era possível ensinar estatística para todos os trabalhadores. Concentraram, então, esforços no treinamento de pessoas para desenhar gráficos que, embora simples, resolvessem a maior parte dos problemas. Nesse sentido, Rossato (1996), explica que o objetivo das 
ferramentas da qualidade é eliminar ou reduzir as fontes de problemas em produtos e serviços. Gozzi (2015) explica que quando aplicadas devidamente, as ferramentas da qualidade podem levar a organização a:

- Elevar os níveis de qualidade, por meio da solução eficaz de problemas;

- Diminuir os custos, com produtos e processos mais uniformes;

- Executar projetos melhores;

- Melhorar a cooperação em todos os níveis da organização;

- Identificar problemas existentes em processos, fornecedores e produtos;

- Identificar as causas-raízes dos problemas e solucioná-las de maneira eficaz.

Para Barros e Bonafini (2015), o trabalho de Ishikawa, foi importante na difusão de ferramentas e técnicas de análise, solução de problemas e gerenciamento da rotina, em especial as ferramentas da qualidade, mais comumente relacionadas ao controle da qualidade, conforme Quadro 1: Fluxograma, Folha de Verificação, Gráfico de Pareto e Diagrama de Causa e Efeito. Outra ferramenta é o 5W1H que é utilizada em diversas outras áreas da gestão, além da qualidade. Entretanto, Ahmed e Hassan (2003) indicam que nem todas as ferramentas ou técnicas são necessárias numa organização. Existem ferramentas que não acrescentam valor, enquanto outras são imprescindíveis para o bom desempenho de um processo. 
Quadro 1

Ferramentas da qualidade mais comumente utilizadas no controle de qualidade

\section{Ferramentas da qualidade}

Fluxograma $\quad$ É usado para descrever a sequência e interação de processos. Os símbolos utilizados no fluxograma são padronizados, isso para que qualquer pessoa, conhecendo tal simbologia, torne-se capaz de compreender o funcionamento do processo. Sua maior vantagem é o fato de propiciar uma visão completa do processo e delimitar cada uma de suas etapas (Barros \& Bonafini, 2015).

Folha de Verificação Vieira (2012) afirma que a folha de verificação é uma ferramenta preciosa no controle de qualidade porque torna a coleta de dados rápida e automática, economiza tempo, evita as anotações rascunhadas e os desenhos mal feitos.

É um formulário que pode ser desenvolvido em processadores de texto, planilhas eletrônicas ou em qualquer outro aplicativo previamente preparado para coletar dados relacionados, os quais devem ser suficientes para gerar respostas às questões necessárias (Barros \& Bonafini, 2015). É usada para reunir dados sobre a repetição de um evento ou problema. Esses dados podem ser utilizados para criar muitas outras ferramentas, como diagrama de Pareto e histograma (Gozzi, 2015).

Gráfico de Pareto Tem como finalidade mostrar a importância de todas as condições do processo, a fim de escolher o ponto de partida para a solução do problema, identificar sua causa básica e monitorar seu sucesso. Pode ser utilizado para identificar $20 \%$ dos erros que são responsáveis por $80 \%$ dos problemas, conforme foi comprovado em estudos desenvolvidos e analisados por Pareto (Gozzi, 2015).

Slack, Chambers e Johnston (2002), também explicam que a análise de Pareto é baseada no fenômeno que ocorre frequentemente de poucas causas explicarem a maioria dos defeitos. Por exemplo, provavelmente a minoria das receitas de uma empresa venha de poucos consumidores. De maneira similar, relativamente poucos pacientes de um médico vão provavelmente tomar a maioria de seu tempo.

Diagrama de causa e De acordo com Barros e Bonafini (2015), também é conhecido como diagrama de efeito Ishikawa ou espinha de peixe e é utilizado para identificar a relação entre as causas e os efeitos de um processo, buscando-se as circunstâncias e analisando cada uma das dimensões ou os "6 Ms", que são: materiais, mão-de-obra, método, máquina, medição e meio ambiente.

Gozzi (2015) afirma que é uma ferramenta utilizada para apresentar a relação entre um resultado de um processo (efeito) e os fatores (causas) do processo que possam afetar o resultado. Visa identificar, explorar e ressaltar todas as causas possíveis de um problema ou de uma condição específica.

$5 \mathrm{~W} 1 \mathrm{H}$

5W (What, Why, De acordo com Gozzi (2015), é uma ferramenta utilizada para estabelecer um Where, Who e When) Na mesma linha de pensamento, Bond, Busse e Pustilnick (2012) consideram que é $1 \mathrm{H}$ ( How) utilizada para colocar uma decisão em prática e geralmente é aplicada após o uso de um brainstorming, de um check-list ou, ainda, de um diagrama de causa e efeito. Tem o objetivo de definir premissas em um projeto, uma decisão ou um plano de ação. Martins e Laugeni (2005) acrescentam que o $5 \mathrm{~W} 1 \mathrm{H}$ pode ser usado como ferramenta de melhoria de produtos ou de processos em serviços, basta fazer as devidas adaptações.

Seleme (2015) cita a ferramenta como essencial para o aumento do desempenho nas atividades de manutenção. Segundo o autor, ela se refere à utilização de perguntas, originadas da língua inglesa, que têm o objetivo de obter respostas que esclareçam o problema a ser resolvido ou que estruturem a utilização de ideias na resolução de problemas. Ele explica ainda que, originalmente, eram somente $5 \mathrm{Ws}$ e $1 \mathrm{H}$; então, um último $\mathrm{H}$, significando How much, foi acrescentado ao método, num momento posterior, para fundamentar financeiramente a decisão tomada.

Fonte: Elaborado a partir de Barros e Bonafini (2015); Vieira (2012); Gozzi (2015); Slack, Chambers e Johnston (2002); Bond, Busse e Pustilnick (2012); Martins e Laugeni (2005); Seleme (2015). 
Pacheco (2012) afirma que o contexto em que são aplicadas as ferramentas é determinante para a escolha da ferramenta ou das ferramentas que serão usadas. No entanto, para a implementação de ferramentas da qualidade numa organização deve-se ter em conta se existem todos os recursos necessários para uma correta utilização das mesmas. Pyo (2005) indica que usar uma ferramenta da qualidade em combinação com outras ferramentas produz melhores resultados e com diferentes perspectivas. Após essa explanação e contextualização sobre gestão da qualidade e ferramentas da qualidade, à luz da literatura disponível, faz-se necessária também à construção de uma compreensão acerca do serviço de manutenção e seus tipos, com destaque para a manutenção corretiva e análise de falhas.

\subsection{Manutenção}

Sabe-se que é crucial para as organizações manter um adequado controle da qualidade dos serviços que oferecem, seja para o consumidor final, ou aqueles oferecidos de um setor para outro, como é o caso da empresa foco desse estudo. Dessa forma, a pesquisa se dá no ambiente de um setor de manutenção de uma petroquímica e cabe ressaltar que, neste caso, o cliente é interno, ou seja, a manutenção não é a atividade fim da empresa, mas um processo intermediário, de modo que o serviço é oferecido a outro setor (produção é cliente da manutenção). Conforme Pinto (2001), a função manutenção dentro da empresa representa um alto potencial de contribuição para o aumento de produtividade, à luz de seu relacionamento com a função produção.

A função manutenção, em tempos de intensa competição e de sobrevivência entre mercados globalizados internos e externos, vem recebendo especial atenção dos mais diversos setores de atuação de uma empresa, especialmente a partir das últimas décadas do século passado, alcançando praticamente todos os níveis hierárquicos. Isso ocorre em razão da necessidade fundamental de controle de custos operacionais, dos quais os de manutenção fazem parte e representam um dos grandes componentes de custos controláveis (Lucatelli, 2002). Nunes (2001) complementa que o impacto de uma manutenção inadequada e ineficiente, pelo aumento dos custos, pode influir na rentabilidade do negócio e na sobrevivência da própria organização. Assim, o setor de manutenção de uma empresa desempenha um papel cada vez mais importante na dinâmica dos sistemas de produção.

A evolução histórica da manutenção e dos processos industriais é abordada por (Moubray, 2000 apud Nunes, 2001) com base em três gerações distintas. A primeira geração representou a ênfase no conserto após a falha. A segunda geração, por sua vez, esteve associada ao surgimento de maiores exigências com relação à disponibilidade operativa e a vida útil dos equipamentos, a custos menores. Já a terceira geração, que se refere aos tempos atuais, diz respeito aos requisitos característicos, como: 
maior disponibilidade, confiabilidade, segurança e vida útil, com ausência de danos ao meio-ambiente e ações de manutenções eficazes, aliadas aos custos envolvidos (Nunes, 2001).

O termo manutenção, segundo (Monchy, 1989 apud Wyrebski, 1997) tem origem no âmbito militar, no qual significa "manter" níveis constantes de efetivo e provisões, passando a ser aplicado na indústria apenas no período pós-Segunda Guerra Mundial (1950) nos Estados Unidos. Segundo a Associação Brasileira de Normas Técnicas - ABNT, resumidamente, manutenção é a combinação de todas as ações técnicas e administrativas, que se destinam a manter ou retornar um item a um estado no qual possa desempenhar uma função requerida (Lucatelli, 2002). Furmann (2002) afirma que em outras palavras, a manutenção deve saber aplicar os conceitos de correção, prevenção e predeterminação para o alcance de um objetivo, com a quantificação dos respectivos níveis de desempenho, sem deixar de fazer gestão dos aspectos econômicos envolvidos, assegurando que as atividades requeridas conduzam a um custo global otimizado. Como premissa estabelece que manter significa dominar, diferente de conservar que significa submeter o material, a fim de assegurar a continuidade da produção.

Segundo Seleme (2015), a postura das fábricas, bem como a do setor de manutenção, mudou nas últimas décadas, de maneira que se busca realizar um trabalho limpo e organizado, estruturado de forma mais planejada em função das crescentes metas de produtividade. Este mesmo autor classifica a manutenção em três tipos: preventiva, corretiva e preditiva. $\mathrm{O}$ autor descreve a manutenção preventiva como o cuidado que é realizado pelo pessoal da manutenção para manter equipamentos e instalações em uma condição satisfatória de operação. Já a manutenção preditiva consiste em monitorar parâmetros dos equipamentos a fim de identificar o momento certo para a realização da manutenção.

Sobre manutenção corretiva, Xenos (2014) explica que ela sempre é feita depois que a falha ocorreu, logo, a opção por este método de manutenção deve levar em conta fatores econômicos como, por exemplo, analisar se é mais barato consertar uma falha do que tomar ações preventivas. Também não se pode esquecer de levar em conta as perdas por paradas na produção, que podem tornar a manutenção corretiva ainda mais cara do que se imaginava a princípio. Nunes (2001) complementa que deve-se considerar também que a falha pode ocorrer, a despeito dos esforços no sentido de prevenir sua ocorrência, ou seja, em tese, se não existissem falhas não haveria manutenção. Sendo assim, a manutenção deve ser desenvolvida para identificar as possíveis falhas, além de gerenciar suas consequências, com técnicas economicamente adequadas a serem aplicadas em cada situação específica.

Dentro desse contexto, conforme explica Slack, Chambers e Johnston (2002), uma das atividades críticas para uma organização quando uma falha ocorre é entender sua causa. Esta atividade é chamada análise de falhas e há diversas técnicas e abordagens que são usadas para descobrir a causa primeira de falhas. A falha de uma máquina pode ter sido causada pelo projeto ruim ou má manutenção, 
por uma falha na entrega, por erros na gestão dos programas de fornecimentos e por erro de um cliente, ou pela falha de alguém em fornecer instruções adequadas. As falhas são raramente o resultado de aleatoriedades; sua causa primeira normalmente é falha humana. As consequências disso são primeiro, que a falha pode, até certo ponto, ser controlada; e segundo, que as organizações podem aprender com as falhas e consequentemente modificar seu comportamento (Slack, Chambers \& Johnston, 2002).

Diante do exposto, a manutenção passa a ser encarada como um processo de negócio dentro da organização, tendo então função estratégica, deixando de ser apenas operacional. Através de uma visão moderna a atividade está sempre vinculada ao sucesso do negócio e não como um fim em si mesma, conforme cita Pinto (2001, p.22), "para que a manutenção possa contribuir efetivamente para que a empresa caminhe rumo a excelência empresarial, é preciso que a sua gestão seja feita com uma visão estratégica". As características de gestão se equilibram com as características técnicas, objetivando um gerenciamento efetivo das atividades, baseando-se em indicadores que espelham o que está acontecendo com o equipamento (Fabro, 2003).

\section{Metodologia}

O presente trabalho busca chegar aos objetivos propostos por meio de uma pesquisa classificada quanto à natureza como aplicada possuindo um viés prático, pois, utiliza as ferramentas da qualidade de forma prática para análise das falhas no serviço de manutenção de uma petroquímica, quanto à forma de abordagem do problema em quali-quantitativa, qualitativa já que os resultados tecem a verificação da relação entre a realidade e o objeto de estudo, buscando-se interpretações analíticas indutivas por parte do pesquisador (Ramos; Ramos; Busnello, 2003) e quantitativa por analisar o Diagrama de Pareto por meio de análises estatísticas e quanto aos objetivos como descritiva, pois descreve as principais características por meio das ferramentas da qualidade. Assim, após a exploração dos fatos, estes foram descritos revelando as características que fazem parte do fenômeno estudado.

Como instrumento de coleta, foram realizadas entrevistas semiestruturadas com os líderes responsáveis (engenharia e supervisão) do setor de manutenção da empresa petroquímica estudada acerca de questionamentos de como era realizado o serviço de manutenção, qual o tipo de manutenção merecia mais atenção atualmente e quais as principais dificuldades e/ou necessidades do setor.

Após a especificação do serviço de manutenção corretiva, através de levantamento de campo e observação participante, foram realizadas três visitas à oficina de manutenção no mês de agosto de 2017, no intuito de conhecer mais profundamente o processo do serviço. O mapeamento foi feito através de fluxograma utilizando o software Bizagi Modeler ${ }^{\circledast}$. 
O software Bizagi Modeler ${ }^{\circledR}$ que é uma ferramenta livre, específica para o mapeamento de processos possibilitando que o analista desenvolva o desenho do processo e detalhe todas as tarefas pertencentes aos processos, podendo inclusive gerar a partir dela relatórios e páginas web para publicação (Flores, 2014, p. 326).

Por meio da análise documental, foi utilizada como folha de verificação, uma planilha obtida a partir de uma busca no sistema integrado de gestão utilizado na empresa, contendo todos os dados das manutenções corretivas necessários para posterior análise. Seguiu-se com aplicações sequenciadas dos Gráficos de Pareto para escalonamento e isolamento das principais falhas para a empresa, ou seja, aquelas responsáveis pelos maiores tempos de paradas nas operações. Após a análise dos dados e identificação das falhas mais representativas, foi feita uma análise conjunta, entre a pesquisadora e os líderes responsáveis a, para construção do Diagrama de Ishikawa, explorando e identificando as causas possíveis do problema e, por fim, foi proposto um plano de ação para mitigação dessas causas a partir do modelo $5 \mathrm{~W} 1 \mathrm{H}$, que é a técnica empregada para descrever informações acerca de um processo (Gomes et al, 2018).

\section{Resultados e discussão}

\subsection{Caracterização da empresa estudada}

Essa pesquisa foi realizada no ambiente de uma empresa brasileira do ramo petroquímico, presente também em vários outros países, com mais de 60 anos no mercado. A unidade na qual se desenvolveu o estudo se localiza em Mossoró/RN. Dentro da empresa foi escolhido como objeto de estudo o serviço de manutenção corretiva prestado por uma oficina que realiza este e outros tipos de manutenções em equipamentos de intervenção em poços de óleo e gás. O setor possui em torno de 40 colaboradores, de várias especialidades técnicas: mecânica, elétrica, corte e solda, pintura, planejadores de manutenção e inspeção, líderes de manutenção, supervisor e engenheiro.

\subsection{Ferramentas da qualidade para análise das falhas}

\subsubsection{Fluxograma}

Para uma melhor compreensão do processo estudado, foi feito um mapeamento das etapas do

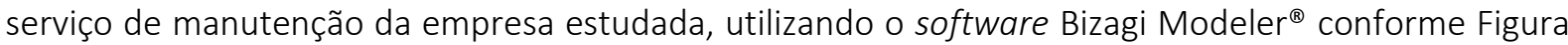
1. O processo da atividade de manutenção corretiva inicia com o recebimento de uma solicitação da manutenção por parte do pessoal da operação prejudicada em virtude das falhas. Caso esta solicitação seja fora do horário administrativo, à noite, por exemplo, deve ser feito um contato com o supervisor para que o mesmo providencie o diligenciamento das equipes que trabalham nesse horário diferenciado. 
Se a solicitação for em horário administrativo, o pessoal da operação deve enviar um e-mail para a manutenção; os planejadores de manutenção, por sua vez, vão providenciar a criação da ordem de serviço. Deve-se analisar a necessidade de material sobressalente para a execução da manutenção. Se não for necessário, segue-se com a execução da manutenção. Caso seja necessário material, podese verificar a existência do mesmo em estoque e até a recuperação ou confecção do item; a confecção de um item sobressalente costuma ser feita em outra oficina de manutenção da empresa, maior e mais especializada. Por último, se nenhuma dessas opções for possível, cria-se uma reserva do material para ser retirado em algum depósito da empresa ou solicita-se a compra do mesmo, o que ocorre apenas em horário administrativo.

Tendo conseguido o material necessário, é executada a manutenção. Após a execução, o equipamento, passa por uma vistoria a fim de identificar se o serviço ocorreu dentro do previsto e o mesmo já está apto para operação novamente. Quando o serviço não ocorre como esperado, ou a manutenção não foi realizada a contento, ou seja, não conseguiu reestabelecer o estado de pleno desempenho da função requerida do equipamento, é solicitado apoio técnico especializado e a manutenção pode precisar ser realizada novamente, ou fora da empresa, ou em outra oficina mais especializada dentro da própria empresa. Quando a manutenção é aprovada e liberada após a vistoria, entrega-se o equipamento para uso da operação e segue-se com o fechamento da nota e ordem de serviço, anexando essa documentação digitalizada no sistema de gestão e encerrando-se, assim, o processo da manutenção corretiva. 
Figura 1

Fluxograma do processo de manutenção corretiva

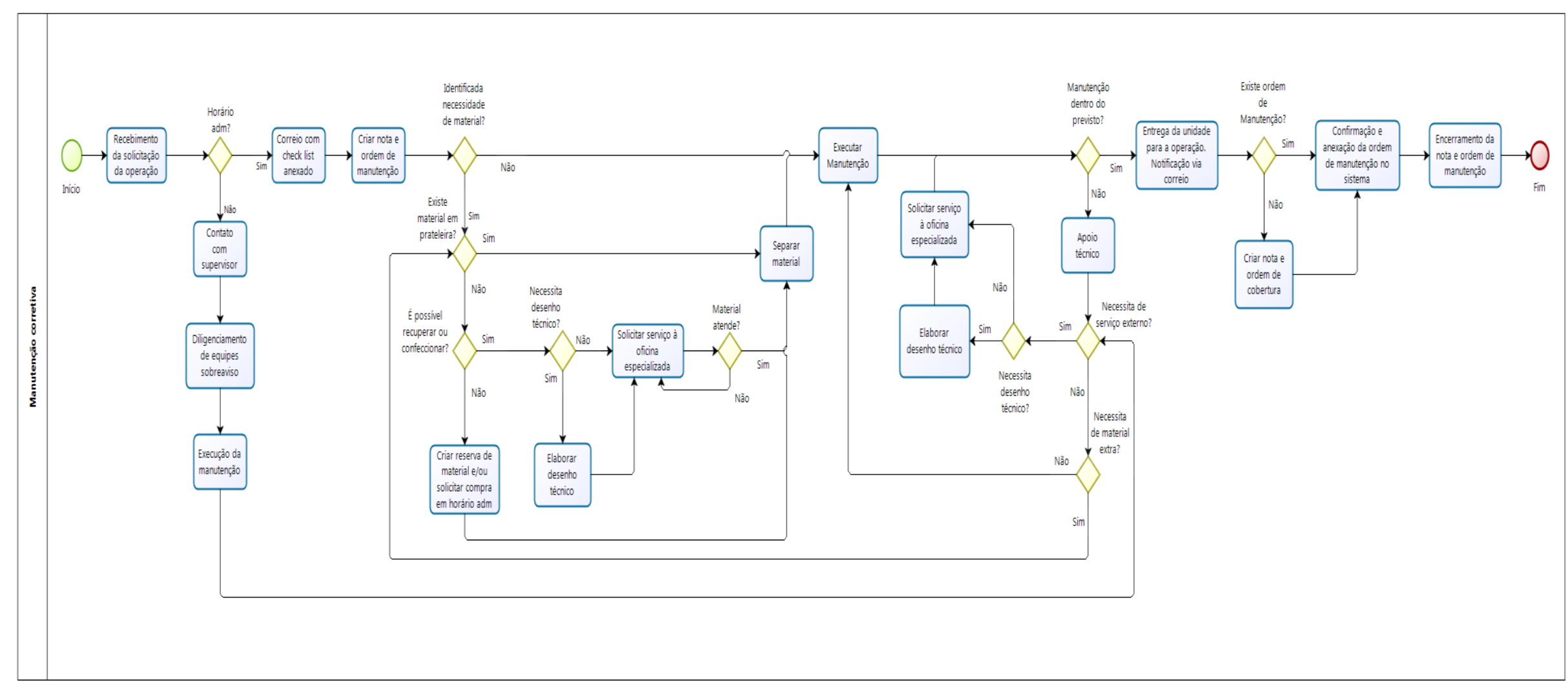

Fonte: Elaboração da autora com dados da pesquisa (2017). 


\subsubsection{Folha de verificação}

Após o mapeamento do serviço de manutenção por meio do fluxograma, foi analisada a folha de verificação. Tendo em vista que a folha de verificação deve conter dados claros, que facilitem a análise e o tratamento posterior, seguindo as particularidades do processo, neste estudo foi utilizada uma planilha, extraída do próprio sistema integrado de gestão utilizado pela empresa. A planilha contemplou todos os dados necessários para a análise das falhas. O levantamento contou com mais de 800 registros de falhas, que deram origem a manutenções corretivas, em um período de 30 meses corridos, entre os anos de 2014 e 2016. Como esse volume de dados torna inviável a apresentação da folha de verificação completa neste artigo, a Tabela 1 traz apenas uma demonstração ou exemplo da planilha utilizada.

\section{Quadro 2}

Folha de verificação

\begin{tabular}{|c|c|c|c|c|c|c|c|c|}
\hline Equipamento & Componente & Descrição da falha & Grupo de falha & Data início & Hora início & Data fim & Hora fim & $\begin{array}{l}\text { Duração } \\
\text { (horas) }\end{array}$ \\
\hline$x$ & 1 & Falha A & Falhas mecânicas & $13 / 04 / 2014$ & 08:00:00 & $13 / 04 / 2014$ & $17: 45: 00$ & 9,75 \\
\hline $\mathrm{Y}$ & 2 & Falha B & Falhas elétricas & 25/10/2015 & 11:00:00 & $25 / 10 / 2014$ & $17: 25: 00$ & 6,42 \\
\hline Z & 3 & Falha C & Falhas mecânicas & $26 / 08 / 2016$ & 15:10:00 & $26 / 08 / 2014$ & 16:30:00 & 1,33 \\
\hline
\end{tabular}

Fonte: Dados extraídos da empresa estudada entre os anos de 2014 a 2016.

Tomando por base a demonstração da Tabela 1, as falhas A e C decorrem de problemas mecânicos que são denominados de grupos de falhas mecânicas por serem várias falhas mecânicas encontradas, com duração de tempo de parada de 9,75 e 1,33 horas, respectivamente. A falha B, com duração de 6,42 horas pertence ao grupo de falhas elétricas, por conter várias falhas elétricas. Além da folha de verificação tornar a coleta de dados rápida, neste caso foi possível responder questões como: tipo e descrição dos eventos; datas em que ocorrem; frequência e duração das paradas. Essas informações são importantes para a posterior análise e priorização do tratamento das não conformidades. Em seguida, todos os grupos de falhas apresentados no conjunto de dados serão contemplados no Diagrama de Pareto.

\subsubsection{Diagrama de Pareto}

Por entendimento da empresa e, especialmente, dos líderes de manutenção envolvidos, neste estudo, o critério de "duração da parada" é mais relevante do que o critério de "frequência", para identificar as falhas mais importantes. Como já foi exposto, a própria literatura explica que a 
manutenção se torna mais dispendiosa em função do tempo em que a operação fica parada aguardando o retorno do equipamento. Desta forma, após a análise dos dados através da folha de verificação, foi aplicado o Diagrama de Pareto para identificar a ordem de importância dos grupos de falhas por tempo de parada, conforme Figura 2.

\section{Figura 2}

Diagrama de Pareto dos grupos de falhas

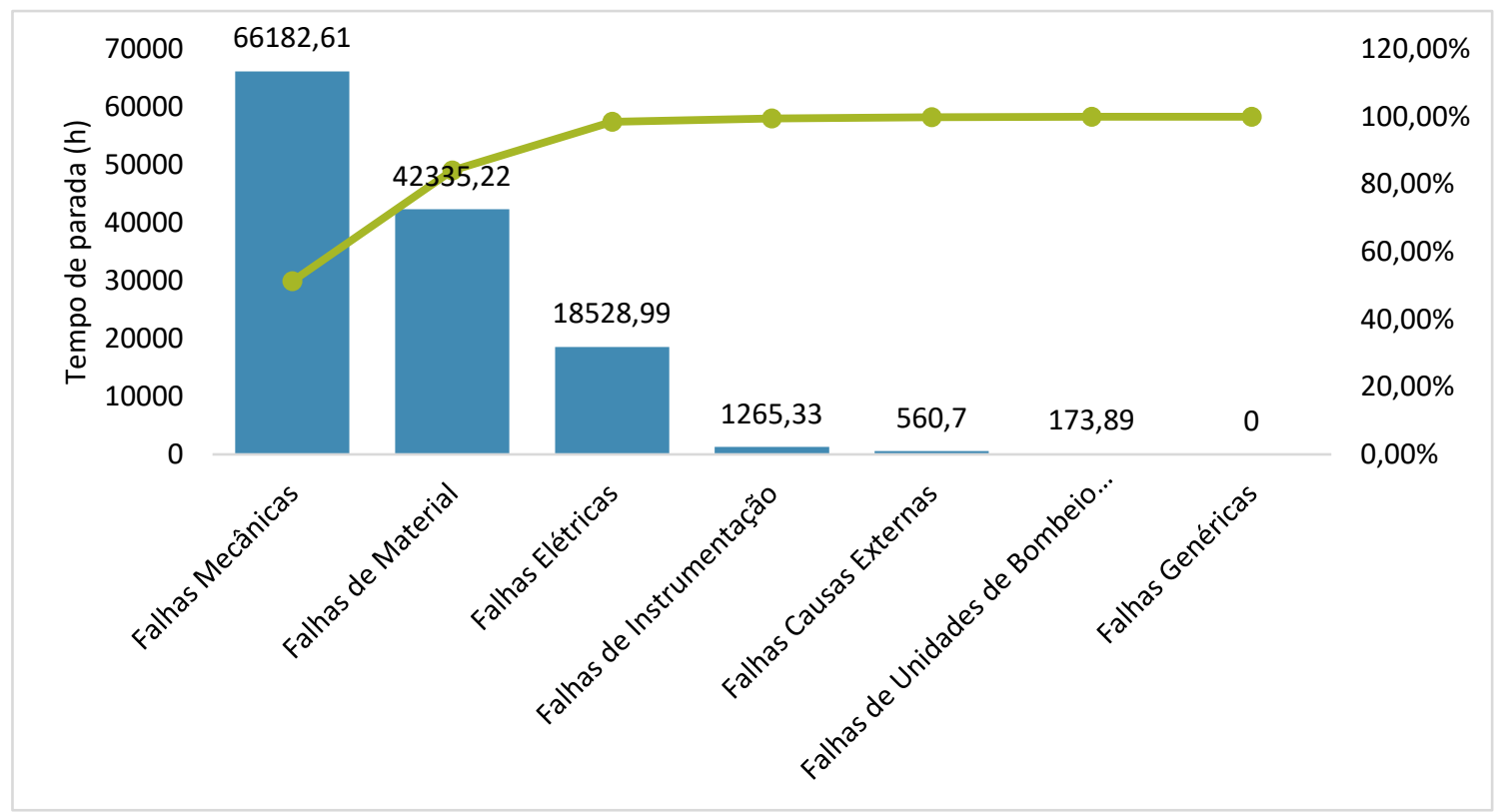

Fonte: Elaborada pela autora com dados da pesquisa (2017).

Após análise quantitativa (em horas) por grupos de falhas, evidenciou-se que as falhas mecânicas são responsáveis pelo maior valor, representando 51,29\% de todo o tempo indisponível dos equipamentos. Desta forma, foi gerado outro Digrama de Pareto apenas para as falhas mecânicas, a fim de ordenar os equipamentos que apresentaram esse tipo de falha, também em função do tempo de parada, conforme Figura 3. 
Figura 3

Diagrama de Pareto dos equipamentos com falhas mecânicas

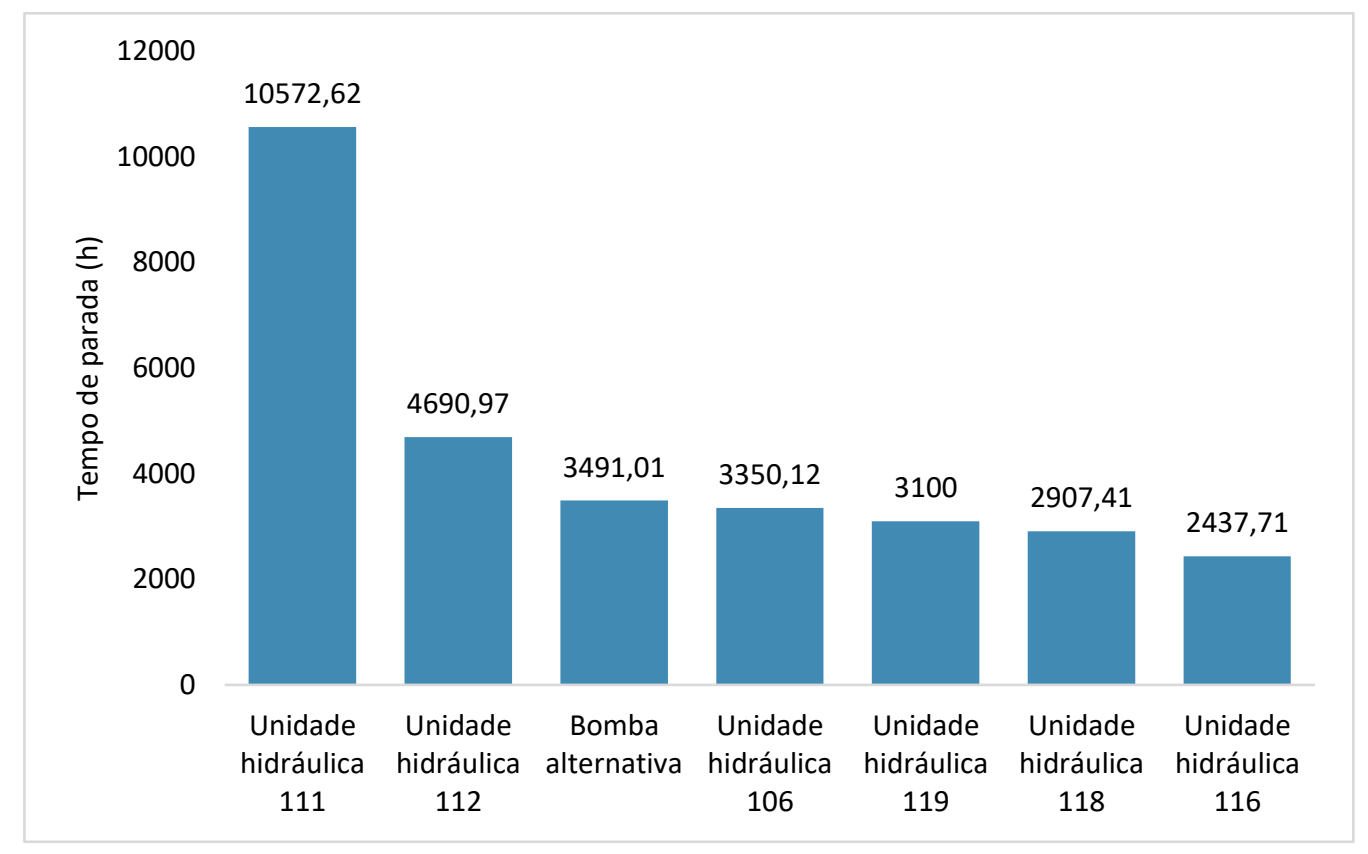

Fonte: Elaborado pela autora com dados da pesquisa (2017).

De acordo com a Figura 3, o gráfico apresentado traz apenas os valores mais representativos em virtude da quantidade de equipamentos (97 no total, somando 66.182,61 horas de parada), no qual, tornou-se inviável a plotagem de todos os itens. Dessa forma, foi possível verificar conforme Figura 3 , que a Unidade Hidráulica 111 despontou como o item mais significativo, responsável por 16\% do tempo total de paradas por falhas mecânicas. Tendo obtido o equipamento mais crítico, mais uma vez foi utilizado o Diagrama de Pareto no intuito de estratificar as falhas por componentes da Unidade Hidráulica 111, conforme Figura 4. 
Figura 4

Diagrama de Pareto dos componentes falhos da Unidade Hidráulica 111

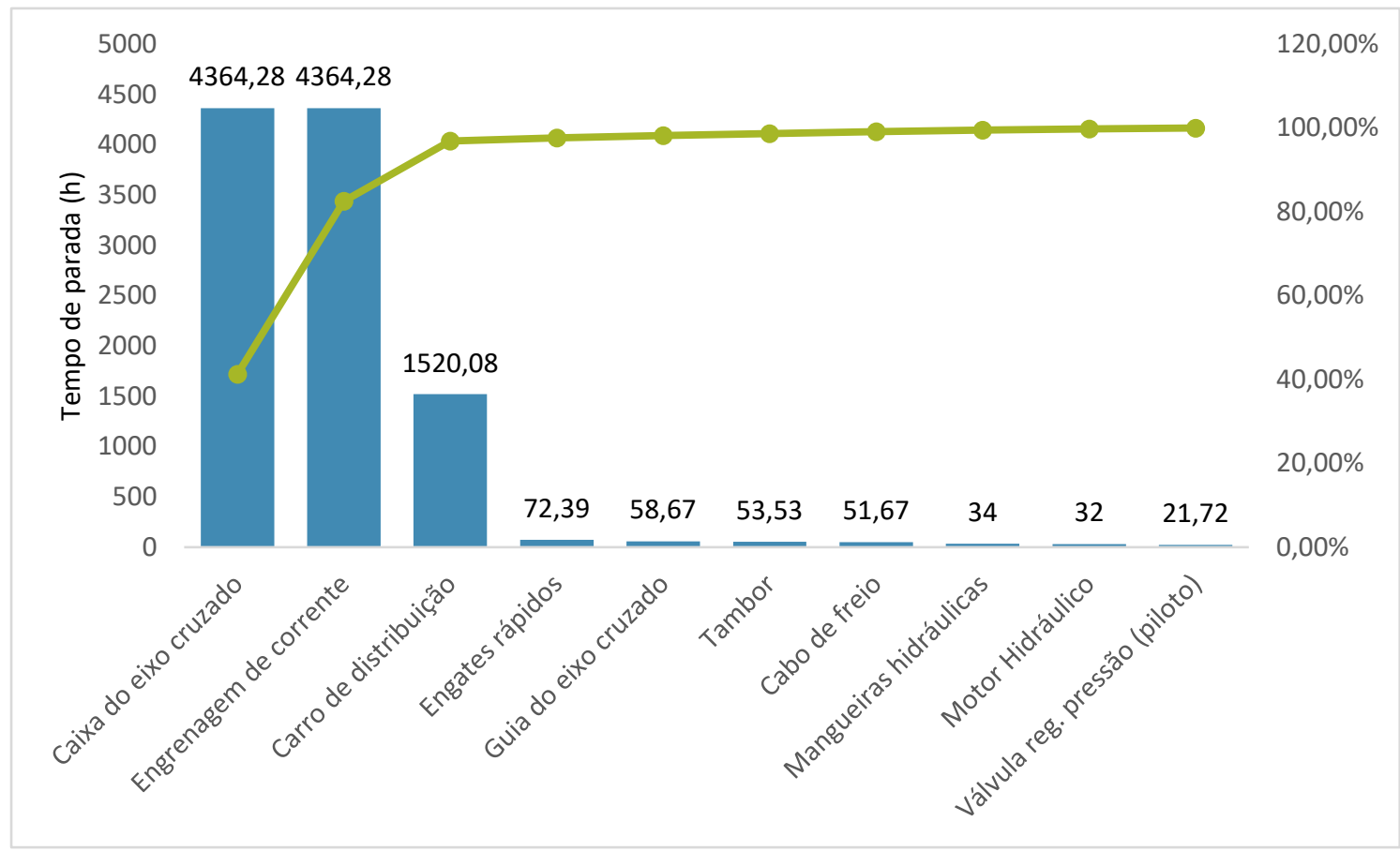

Fonte: Elaborado pela autora com dados da pesquisa (2017).

De acordo com a Figura 4, o histórico disponível das manutenções corretivas desse equipamento nos mostra que os maiores tempos de parada correspondem a problemas com a Caixa do Eixo Cruzado e Engrenagem de Corrente, apresentando 4364,28 horas para cada um desses itens. Com isso, foi obtido o ponto de partida para a solução dos problemas e a ordem de importância a ser seguida, que é o que propõe essa ferramenta. O próximo passo é identificar as causas básicas por meio do Diagrama de Ishikawa.

\subsubsection{Diagrama de Ishikawa}

Com o objetivo de explorar e identificar as possíveis causas para as falhas na Caixa do Eixo Cruzado foi elaborado um Diagrama de Ishikawa, conforme Figura 5. A partir deste ponto, faz-se necessário reforçar que o trabalho foi feito em conjunto com os líderes de manutenção entrevistados, que são grandes interessados em um resultado com propostas factíveis a curto e médio prazo. Cabe ressaltar que, possivelmente, existem causas de caráter mais técnico, que estariam inseridas nas categorias "medida" e "materiais", mas por entendimento dos próprios líderes da equipe e por indisponibilidade dos dados por parte da empresa, essas não entraram no escopo desse estudo. 
Figura 5

Diagrama de Ishikawa para as falhas na Unidade Hidráulica 111

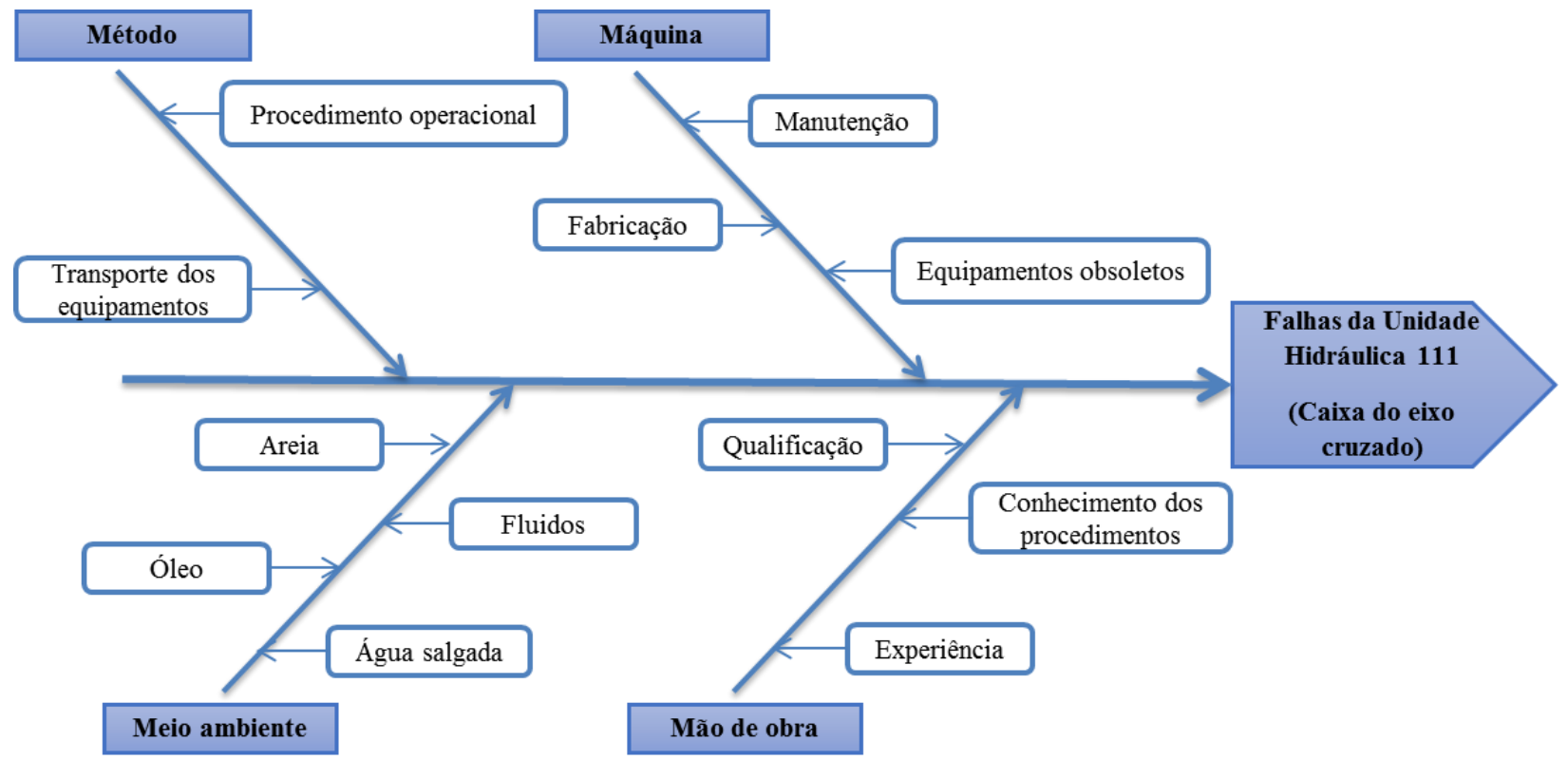

Fonte: Elaborado pela autora com dados da pesquisa (2017).

De acordo com a Figura 5, sobre as causas relacionadas ao meio ambiente, entende-se que não podem ser evitadas, pois são condições adversas inerentes ao processo produtivo na indústria petrolífera. Em relação à mão de obra, um ponto importante e de resolução simples é que os operadores das unidades conheçam os procedimentos operacionais padrão da atividade, buscando evitar manuseio ou uso inadequado que podem incorrer não só em problemas com a caixa do eixo cruzado, mas também de outra natureza. Na dimensão máquina, os líderes da manutenção praticamente desconsideram problemas de fabricação ou a possibilidade do equipamento estar obsoleto; mas um ponto de atenção e de resolução interna é a garantia de que a manutenção anterior foi realizada adequadamente.

Já no que diz respeito aos métodos utilizados, além de fazer os operadores conhecerem os procedimentos operacionais, é necessário garantir que eles estão sendo seguidos à risca no momento da operação. Conforme explicação de Slack, Chambers e Johnston (2002), sabe-se que a origem de todas as falhas está em algum tipo de erro humano. Por esta razão, a falha pode ser controlada até certo ponto e as organizações podem aprender com as falhas, modificando o comportamento a partir do fator humano. O plano de ação traçado se baseia exatamente nesse pensamento.

\subsubsection{Plano de ação (5W1H)}

A partir das percepções acima expostas, foi elaborado como sugestão um plano de ação, conforme Quadro 2 com base no modelo 5W1H. Não serão tratadas as questões de custos neste caso. As dimensões contempladas no plano são: mão de obra, máquina e método. Na dimensão meio 
ambiente, conforme já foi explicado, as condições adversas são inerentes ao processo e fogem do controle da empresa. Pelo próprio interesse da equipe, nem todas as causas foram exploradas, mas sim aquelas consideradas mais significativas e com maior possibilidade de resolução rápida e sem custos adicionais para o setor. 


\section{. . . ."הHH}

Quadro 2

\section{Plano de ação}

\begin{tabular}{|c|c|c|c|c|c|c|}
\hline ITEM & $\begin{array}{l}\text { O QUE? } \\
\text { (What?) }\end{array}$ & $\begin{array}{l}\text { PORQUE? } \\
\text { (Why?) }\end{array}$ & $\begin{array}{l}\text { ONDE? } \\
\text { (Where?) }\end{array}$ & $\begin{array}{l}\text { QUEM? } \\
\text { (Who?) }\end{array}$ & $\begin{array}{l}\text { QUANDO? } \\
\text { (When?) }\end{array}$ & $\begin{array}{l}\text { COMO? } \\
\text { (How?) }\end{array}$ \\
\hline $\begin{array}{l}\text { Mão de } \\
\text { obra }\end{array}$ & $\begin{array}{l}\text { Treinamento em padrões } \\
\text { operacionais }\end{array}$ & $\begin{array}{l}\text { Para garantir o conhecimento do } \\
\text { procedimento padrão para } \\
\text { operar o equipamento }\end{array}$ & $\begin{array}{l}\text { Atividades de campo e } \\
\text { oficina }\end{array}$ & $\begin{array}{l}\text { Líderes da manutenção } \\
\text { e operação }\end{array}$ & out/17 & $\begin{array}{lr}\text { Revisar padrões atuais, } \\
\text { atualizar, se necessário, } \\
\text { disseminar entre os } \\
\text { operadores } \\
\text { leitura/conhecimento } \\
\text { realizar treinamentos práticos }\end{array}$ \\
\hline Máquina & $\begin{array}{l}\text { Check-list pós- } \\
\text { manutenção }\end{array}$ & $\begin{array}{l}\text { Para garantir a eficiência da } \\
\text { manutenção corretiva, evitando } \\
\text { um retorno prematuro do } \\
\text { equipamento }\end{array}$ & Oficina de manutenção & $\begin{array}{l}\text { Supervisor da atividade } \\
\text { de manutenção }\end{array}$ & out/17 & $\begin{array}{l}\text { Criar e tornar imperativa a } \\
\text { realização do Check-list pós- } \\
\text { manutenção, contendo a } \\
\text { verificação da eficácia de todos } \\
\text { os itens da lista de tarefas da } \\
\text { manutenção. Montar também } \\
\text { desenho esquemático com o } \\
\text { principio de funcionamento do } \\
\text { equipamento para gerar senso } \\
\text { preventivo nos mantenedores }\end{array}$ \\
\hline Método & $\begin{array}{l}\text { Verificar a conformidade } \\
\text { da operação com o } \\
\text { padrão }\end{array}$ & $\begin{array}{l}\text { Para mitigar as falhas causadas } \\
\text { por erro de procedimento no uso } \\
\text { da unidade }\end{array}$ & $\begin{array}{l}\text { Atividades de campo e } \\
\text { oficina }\end{array}$ & $\begin{array}{l}\text { Líderes da manutenção } \\
\text { e operação }\end{array}$ & $\mathrm{dez} / 17$ & $\begin{array}{l}\text { Verificar desvios que possam } \\
\text { gerar danos aos equipamentos } \\
\text { em operação }\end{array}$ \\
\hline Método & $\begin{array}{l}\text { Garantir o transporte } \\
\text { adequado dos } \\
\text { equipamentos }\end{array}$ & $\begin{array}{l}\text { Evitar avarias durante o } \\
\text { transporte terrestre e marítimo } \\
\text { dos equipamentos }\end{array}$ & $\begin{array}{l}\text { Na atividade de } \\
\text { transporte }\end{array}$ & $\begin{array}{l}\text { Supervisor da atividade } \\
\text { de manutenção }\end{array}$ & $\mathrm{dez} / 17$ & $\begin{array}{l}\text { Disseminar entre os } \\
\text { motoristas, ajudantes e } \\
\text { demais pessoas envolvidas no } \\
\text { transporte dos equipamentos, } \\
\text { a necessidade de acomodação } \\
\text { e cuidados adequados no } \\
\text { sentido de evitar avarias }\end{array}$ \\
\hline
\end{tabular}


Assim como é apresentada na literatura, a ferramenta $5 \mathrm{~W} 1 \mathrm{H}$ foi usada nesse estudo para colocar em prática as decisões tomadas em conjunto (pesquisadora e equipe técnica da empresa) a partir da aplicação de um diagrama de causa e efeito. O resultado fornece para a empresa não só as propostas de ações, mas um cronograma de planejamento para a execução.

As ferramentas utilizadas para esse estudo seguiram uma ordem de execução para que primeiro fossem mapeadas as etapas do serviço de manutenção para o conhecimento amplo do setor de estudo. Em seguida foi analisada a folha de verificação da empresa para a análise das falhas que deram origem a manutenções corretivas. Logo após, foi elaborado o diagrama de Pareto para identificar a ordem de importância dos grupos de falhas por tempo de parada. De posse dessas informações, foi também elaborado o diagrama de Ishikawa com o objetivo de explorar e identificar as possíveis causas para as falhas listadas na folha de verificação. Por fim foi proposto como sugestão um plano de ação com base na ferramenta $5 \mathrm{~W} 1 \mathrm{H}$.

\section{Considerações finais}

Entende-se, a partir do exposto, que os objetivos específicos da pesquisa foram atendidos, visto que foi possível obter um mapeamento do processo, identificando suas etapas e variáveis envolvidas, a partir da utilização do Fluxograma; em seguida, após a obtenção dos dados necessários para análise, por meio de uma Folha de Verificação, estes foram organizados e tratados, mediante a construção de gráficos de Pareto, possibilitando o escalonamento das falhas por ordem de importância e identificando aquelas responsáveis pelos maiores tempos de parada de produção; e, por último, foram identificadas as causas das principais falhas, dando origem a um plano de ação para a mitigação dessas causas, com base na ferramenta $5 \mathrm{~W} 1 \mathrm{H}$.

A partir do alcance dos objetivos específicos, pode-se compreender que o objetivo geral também foi atendido, bem como a pergunta de pesquisa foi respondida. Por essas razões e com base no que foi demonstrado neste trabalho, conclui-se que as ferramentas da qualidade podem auxiliar no gerenciamento das falhas, oferecendo a possibilidade de organização dos dados, isolamento das falhas, exploração e identificação das causas e elaboração de planos com direcionamentos para resolução das mesmas. Cabe destacar que foi possível apresentar para a empresa um caminho para a resolução de uma necessidade ou dificuldade apresentada pela própria equipe durante a investigação.

As ações propostas são simples, de implementação praticamente imediata, não geram custos adicionais para o setor e podem contribuir significativamente para a redução ou eliminação das principais causas encontradas. As etapas desenvolvidas na análise dos dados configuram um modelo que pode ser adotado pelo setor de manutenção de forma sistemática, para ordenar ou escalonar os 
problemas, concentrando esforços primeiramente naqueles mais representativos para a gerência e para a empresa como um todo.

Para trabalhos futuros e até para a própria empresa, pode-se sugerir uma análise sequencial dos outros itens apresentados pelos Diagramas de Pareto, estudo de tempo médio entre falhas e tempo médio de reparo. Como dito anteriormente, é possível que existam causas de falhas de cunho mais técnico, no que tange às especificações dos equipamentos, fabricação, materiais ou matéria-prima, estudo de fornecedores etc. Porém, este trabalho não se debruçou sobre essas possibilidades, pelo entendimento de que fazem parte do escopo de outras áreas e necessitam de um estudo mais exaustivo e minucioso. Esta também pode ser uma sugestão para futuros trabalhos ou até para a continuação da investigação por parte do setor de manutenção estudado.

\section{Referências}

Ahmed, S., \& Hassan, M. (2003) Survey and case investigations on application of quality management tools and techniques in SMIs. International Journal of Quality \& Management, 20 (7), p. 795 826. https://doi.org/10.1108/02656710310491221

Almeida, D. A, Leal, F., Pinho, A. F. \& Fagundes, L. D. (2006). Gestão do conhecimento na análise de falhas: mapeamento de falhas através de sistema de informação. Produção, 16 (1), p. 171188. https://doi.org/10.1590/S0103-65132006000100014

Alsaleh, N. A. (2007). Application of quality tools by the Saudi food industry. The TQM Magazine, 19 (2), p. 150-161. https://doi.org/10.1108/09544780710729999

Bamford, D. R., \& Greatbanks, R. W. (2005). The use of quality management tools and techniques: a study of application in everyday situations. International Journal of Quality \& Reliability Management, 22 (4), p. 376-392. https://doi.org/10.1108/02656710510591219

Barros, E., \& Bonafini, F. (2015) Ferramentas da Qualidade. São Paulo: Pearson Education do Brasil.

Bond, M. T., Busse, A., \& Pustilnick, R. (2012) Qualidade total: O que é e como alcançar. Curitiba: Intersaberes.

Brito, A. K. A., Bezerra, I. R. M. \& Oliveira, A. J. (2011, junho). Aplicação das ferramentas de qualidade nos serviços prestados por um supermercado da cidade de Mossoró/RN. Anais do Encontro de Engenharia de Produção - SEPRONE, Campina Grande, PB, Brasil. CD ROM.

Carpinetti, L. C. R. (2012) Gestão da qualidade: conceitos e técnicas. 2. ed. São Paulo: Atlas.

Carnevalli, J. A., Miguel, P. A. C., \& Calarge, F. A. (2008) Proposta de um modelo conceitual para minimizar as dificuldades no uso do QFD. Revista Produção, 18 (1), p. 126-141. https://doi.org/10.1590/S0103-65132008000100010

Chavez, L. M. C. G., \& Medeiros, F. E. (1998, setembro). Engenharia de manutenção: fator de mudança. Anais do 13 Congresso Brasileiro de Manutenção, ABRAMAN, Salvador, BA, Brasil. CD ROM. 
Coelho, F. P. S., Silva, A. M., \& Maniçoba, R. F. (2016). Aplicação das ferramentas da qualidade: estudo de caso em pequena empresa de pintura. Refas - Revista Fatec Zona Sul, 3 (1), p. 31-45. Recuperado em 29 de setembro, 2018 de http://www.revistarefas.com.br/index.php/RevFATECZS/article/view/70/97

Corrêa, H. L., \& Gianesi, I. G. N. (2012) Administração estratégica de serviços: operações para satisfação dos clientes. 1 ed. São Paulo: Atlas.

Costa, L. G. G. (2017). Comparação das ferramentas da qualidade em duas indústrias brasileiras. Trabalho de Conclusão de Curso - Especialização. Universidade Tecnológica Federal do Paraná, Ponta Grossa, Brasil. Recuperado em 30 de setembro, 2018 de http://repositorio.utfpr.edu.br/jspui/handle/1/23231

Courtney, P. (2005) Time management using quality tools. American Society for Quality. Recuperado em 25 de outubro, 2018 de http://207.67.83.164/quality-progress/2005/08/six-sigma/timemanagement-quality-tools.html

Crosby, P. (1999) Princípios absolutos de liderança. 3 ed. São Paulo: Makron Books.

Dias, S., \& Saraiva, P. (2004) Use basic quality tools to manage your processes.

Quality Progress, 37(8), p.47-53, Aug 2004. Recuperado em 25 de outubro, 2018 de https://www.researchgate.net/publication/323525653_Use_basic_quality_tools_to_manage_ your_processes.

Fabro, E. (2003) Modelo para planejamento de manutenção baseado em indicadores de criticidade e de processo. Dissertação de Mestrado. Universidade Federal de Santa Catarina - UFSC, Florianópolis, Brasil. Recuperado em 30 de outubro, 2018 de http://repositorio.ufsc.br/xmlui/handle/123456789/84910

Fabris, C. B. (2014). Aplicação das ferramentas da qualidade em um processo produtivo em uma indústria de ração. Trabalho de Conclusão de Curso. Universidade Tecnológica Federal do Paraná, Medianeira, Brasil. Recuperado em 30 de outubro, 2018 de http://repositorio.roca.utfpr.edu.br/jspui/handle/1/4327

Flores, E. G. (2014, setembro) Mapeamento de processos utilizando a metodologia BPM uma ferramenta de suporte estratégico no desenvolvimento de sistemas em uma Instituição Federal de Ensino Superior. Anais Encontro da Tecnologia da Informação - Semana Acadêmica de Tecnologia da Informação, Frederico Westphalen /RS. Recuperado em 20 de outubro, 2018 de http://www.xiwticifes.ufba.br/modulos/submissao/Upload-353/85943.pdf

Furmann, J. C. (2002). Desenvolvimento de um modelo para a melhoria do processo de manutenção mediante a análise de desempenho de equipamentos. Dissertação de Mestrado. Universidade Federal de Santa Catarina - UFSC, Florianópolis, Brasil. Recuperado em 28 de outubro, 2018 de http://repositorio.ufsc.br/xmlui/handle/123456789/82781

Ganim, A. Setor Elétrico Brasileiro - Aspectos regulamentares e tributários. São Paulo: Canalenergia, 2003.

Gomes, A. C. N., et al. (2018) A aplicação das ferramentas da qualidade na criação de procedimentos operacionais padronizados em dois restaurantes de meios de hospedagem no Rio de Janeiro. Exacta - EP, São Paulo, 16 (2), p. 95-106. https://doi.org/10.5585/ExactaEP.v16n2.7066 
Gozzi, M. P. (2015) Gestão da Qualidade em bens e serviços. São Paulo: Pearson Education do Brasil.

Hliouia, R., Gharbia A., \& Hajjib A. (2015) Replenishment, production and quality control strategies in three-stage supply chain. Engineering Costs and Production Economics. International Journal of Production Economics on-line, 166 (1), p. 90-102.

https://doi.org/10.1016/j.ijpe.2015.04.015

Ibge - Instituto Brasileiro de Geografia e Estatística. Agência IBGE notícias. Recuperado em 10 de setembro, 2018 de https://agenciadenoticias.ibge.gov.br/

Ishikawa, K. (1993) Controle da qualidade total à maneira japonesa. Rio de Janeiro: Campus.

Jacobsen, J. (2009). Can a fishbone diagram stop a bully? American Society for Quality. Recuperado em 25 de outubro, 2018 de https://asq.org/quality-resources/articles/case-studies/can-afishbone-diagram-stop-a-bully?id=733d64258236418d9464540e7a1f6fb6

Juran, J. M. \& Gryna, F. M. (1991) Controle da qualidade: handbook - conceitos, políticas e filosofia da qualidade. São Paulo: Makron/McGraw-Hill.

Lacombe, F. J. M., \& Heilborn, G. L. J. (2006) Administração: princípios e tendências. São Paulo: Saraiva.

Lagrosen, S. (2007) Quality management and environment: exploring the connections. International Journal of Quality \& Reliability Management, 24 (4), p. 333-346.

https://doi.org/10.1108/02656710710740527

Laurenti, R. (2010). Sistematização de problemas e práticas da análise de falhas potenciais no desenvolvimento de produtos. 2010. 182 f. Dissertação. Mestrado em Engenharia de Produção. Universidade de São Paulo - Escola de Engenharia de São Carlos, São Carlos. Recuperado em 10 de novembro, 2018 de https://teses.usp.br/teses/disponiveis/18/18156/tde-15092010-093659/pt-br.php

Leal, F. (2008). Análise do efeito interativo de falhas em processos de manufatura através de projeto de experimentos simulados. (2008). 237 f. Tese. Doutorado em Engenharia Mecânica, Universidade Estadual Paulista, Guaratinguetá. Recuperado em 06 de novembro, 2018 de http://hdl.handle.net/11449/106417

Lovelock, C. H., Wirtz, J., \& Hemzo, M. A. (2011) Marketing de serviços: pessoas, tecnologia e estratégia. 7. ed. São Paulo: Pearson.

Lucatelli, M. V. (2002) Proposta de aplicação da manutenção centrada em confiabilidade em equipamentos médicos hospitalares. 2002. 285 f. Dissertação (Mestrado) - Curso de Engenharia Elétrica. Universidade Federal de Santa Catarina - UFSC, Florianópolis, Brasil. Recuperado em 29 de outubro, 2018 de http://repositorio.ufsc.br/xmlui/handle/123456789/84318

Martins, P. G., \& Laugeni, F. P. (2005) Administração da produção. São Paulo: Saraiva.

Matias, G. C. (2014). Utilização de ferramentas da qualidade na busca de melhoria contínua em indústria de alimentos. Revista Especialize On-Line IPOG, 8 (9), p. 1-15. Recuperado em 28 de outubro, 2018 de http://docplayer.com.br/22168985-Utilizacao-de-ferramentas-daqualidade-na-busca-de-melhoria-continua-em-industria-de-alimentos.html 
Mello, C. H. P. (2011) Gestão da qualidade. São Paulo: Pearson Education do Brasil.

Mello, M. F., Araújo, A. C., Cunha, L. A., \& Silva, N. J. (2016, outubro). A importância da utilização de ferramentas da qualidade como suporte para a melhoria de processo em indústria metal mecânica - um estudo de caso. Anais do Encontro Nacional de Engenharia de Produção ENEGEP, João Pessoa, PB, Brasil, 36. Recuperado em 01 de novembro, 2018 de http://www.abepro.org.br/biblioteca/TN_STO_226_323_28620.pdf

Nunes, E. L. (2001). Manutenção centrada em confiabilidade (MCC): análise da implantação em uma sistemática de manutenção preventiva consolidada. 2001. 146 f. Dissertação (Mestrado) Curso de Engenharia de Produção. Universidade Federal de Santa Catarina - UFSC, Florianópolis, Brasil. Recuperado em 30 de outubro, 2018 de http://repositorio.ufsc.br/xmlui/handle/123456789/82056

Pacheco, M. C. S. (2012). O uso das ferramentas da qualidade nas organizações portuguesas. Dissertação de Mestrado. Universidade do Minho, Minho, Portugal. Recuperado em 28 de outubro, 2018 de http://hdl.handle.net/1822/25622

Pinto, A. K. (2001) Manutenção Empresarial. Revista Manutenção - Revista oficial da ABRAMAN, 1(80), março/abril, p. 22. Recuperado em 05 de novembro, 2018 de https://abramanoficial.org.br/page/revista-manutencao

Pyo, S. (2005). Choosing quality tools: 7 tools case. Journal of Quality Assurance in Hospitality \& Tourism, 6 (1/5), p. 12-36. https://doi.org/10.1300/J162v06n01_01

Rausand, M., Oien, K. (1996). The basic concepts of failure analysis. Reliability Engineering and System Safety, 53 (1), p. 73-83. https://doi.org/10.1016/0951-8320(96)00010-5

Ramos, P.; Ramos, M. M.; Busnello, S. J. (2003). Manual prático de metodologia da pesquisa: artigo, resenha, projeto, TCC, monografia, dissertação e tese. Blumenau: Acadêmica.

Rossato, I. F. (1996) Uma metodologia para a análise e solução de problema. 1996. 113 f. Dissertação de Mestrado. Centro Tecnológico, Universidade Federal de Santa Catarina - UFSC, Florianópolis, Brasil. Recuperado em 10 de novembro, 2018 de https://repositorio.ufsc.br/xmlui/handle/123456789/158025

Sakurada, E. Y. (2001). As técnicas de análise dos modos de falhas e seus efeitos e análise da árvore de falhas no desenvolvimento e na avaliação de produtos. 2001. 145 f. Dissertação Mestrado em Engenharia Mecânica. Universidade Federal de Santa Catarina UFSC, Florianópolis, Brasil. Recuperado em 10 de novembro, 2018 de http://repositorio.ufsc.br/xmlui/handle/123456789/80128

Seleme, R. (2015) Manutenção industrial: mantendo a fábrica em funcionamento. Curitiba: Intersaberes.

Seleme, R. (2016) Gestão de operações de serviços: planejando o sucesso no atendimento ao cliente. Curitiba: Intersaberes.

Sergesketter, B. (2004). Create a better life with quality tools. Quality Progress, 37(8), p. 25-30. Recuperado em 25 de outubro, 2018 de http://sq.org/quality-progress/articles/create-abetter-life-with-quality-tools?id=1e1472243bf040f6833f1cc527153993 
Schaar, T. (2010). Quality basics simplify complex engineering document management challenge. American Society for Quality. Recuperado em 25 de outubro, 2018 de https://asq.org/search\#q=Quality\%20basics\%20simplify\%20complex\%20engineering\%20docu ment\%20management\%20challenge\&t=coveod4b530f4\&srt=relevancy

Slack, N., Chambers, S., \& Johnston, R. (2002) Administração da Produção. São Paulo: Atlas.

Sousa, S., Aspinwall, E., Sampaio, P., \& Rodrigues, A. (2005). Performance measures and quality tools in portuguese small and medium enterprises: survey results. Total Quality Management, 16 (2), p. 277 - 307. https://doi.org/10.1080/14783360500054434

Srdoc, A., Sluga, A., \& Bratko, I. (2005) A quality management model based on the "deep quality concept". International Journal of Quality \& Reliability Management, 22 (3), p. 278-302. https://doi.org/10.1108/02656710510582499

Thiraviam, A. (2006). Simple tools for complex systems. Quality Progress, 39(6), p. 40-44. Recuperado em 10 de novembro, 2018 de https://asq.org/quality-progress/articles/simple-tools-forcomplex-systems?id=5e874ec420da40879411a914547540aa

Trivellato, A. A. (2010). Aplicação das sete ferramentas básicas da qualidade no ciclo PDCA para melhoria contínua: estudo de caso numa empresa de autopeças. Trabalho de Conclusão de Curso. Universidade de São Paulo, São Carlos, Brasil. Recuperado em 01 de novembro, 2018 de http://www.tcc.sc.usp.br/tce/disponiveis/18/180830/tce-19012011-162523/?\&lang=br

Vieira, S. (2012) Estatística para a Qualidade. Rio de Janeiro: Elsevier Editora Ltda.

Wyrebski, J. (1997) Manutenção Produtiva Total - Um Modelo Adaptado. 1997. 180 f.

Dissertação (Mestrado) Curso de Engenharia de Produção e Sistemas - Centro Tecnológico, Universidade Federal de Santa Catarina - UFSC, Florianópolis, Brasil. Recuperado em 30 de outubro, 2018 de https://repositorio.ufsc.br/xmlui/handle/123456789/158161

Xenos, H. (2014) Gerenciando a manutenção produtiva. Nova Lima: Falconi. 